\title{
Escenarios de parto y bautismo de urgencia en libros de bautismo del siglo XVII ${ }^{1}$
}

\section{Birthing scenarios and emergency baptism in 17th century parish registers}

\author{
WOLFRAM AICHINGER \\ Universidad de Viena \\ wolfram.aichinger@univie.ac.at \\ ALICE-VIKTORIA DULMOVITS \\ Universidad de Viena \\ alice-viktoria.dulmovits@univie.ac.at
}

Resumen: A lo largo del siglo xVII, en los libros de bautismo parroquiales aumentaron las referencias a bautismos de urgencia administrados durante o justo después del parto. Estas referencias facilitan datos interesantes sobre las circunstancias del nacimiento en la época. Los datos aquí examinados provienen mayormente de la parroquia de San Justo y Pastor y de San Pedro de Barajas y abarcan los años de 1611 a 1663.

Se señalarán algunas tendencias en cuanto al número y a la proporción de bautismos de urgencia, además de las causas de su incremento. También se indicará la posibilidad de ampliar las biografías de destacadas comadronas del siglo. Por último, se debatirán los breves diálogos con tenor de interrogatorio anotados por los sacerdotes de Barajas y su utilidad para reconstruir escenas de parto en el Siglo de Oro y para observar las tareas y responsabilidades de una comadre áurea en los momentos más arduos de su oficio. El problema del bautismo, se concluirá, puede ayudar a comprender mejor el modo en que la sociedad española premoderna afrontó la procreación humana en todas sus fases e implicaciones médicas y sociales.

Palabras clave: escena de parto, bautismo de emergencia, agua de socorro, comadrona, abuela.

\footnotetext{
${ }^{1}$ Este estudio se llevó a cabo en el marco de los proyectos de investigación El Calderón cómico (FWF Austrian Science Fund, P 29115) y The Interpretation of Childbirth in Early Modern Spain (FWF Austrian Science Fund, P 32263-G30). Estamos agradecidos a Nina Kremmel, Hannah Fischer-Monzón, Jesús M. Usunáriz, Dominik Prinz, Rocío Martínez, Laura Oliván, Andrea Sommer-Mathis, Katrin Keller, Don W. Cruickshank, Rocío Martínez, Alessandra Foscati, Costanza Gislon Dopfel, Adela Tarifa Fernández, Antonio Linage Conde, Fernando Rodríguez-Gallego, Marie-France Morel y Abraham Madroñal por sus sugerencias y su ayuda. Modernizamos la ortografía en todas las citas.
}

Recibido: 17 de enero de 2019; aceptado: 21 de noviembre de 2019; publicado: 31 de marzo de 2020.

Revista Historia Autónoma, 16 (2020), pp. 13-35

e-ISSN: 2254-8726; https://doi.org/10.15366/rha2020.16.001 
Abstract: During the $17^{\text {th }}$ century, there is a steady increase of references to emergency baptism in Spain. These references facilitate important insights into the circumstances of childbirth. The data reviewed in this paper mostly stems from the parish registers of San Justo y Pastor and San Pedro de Barajas, and they cover the years from 1611 to 1663. This information reveals some tendencies regarding the number and ratio of infants born in precarious conditions. Moreover, they enable us to widen the biographies of outstanding birth assistants who were active at that time. Interrogations carried out by the parish priest at the baptismal font widen our understanding of birthing scenarios and the actions of midwives. We conclude that the problem of baptism might help to grasp the relevance of religious preoccupations at all stages of procreation and obstetrical care.

Keywords: birthing scene, emergency baptism, baptismal water, midwife, grandmother.

\section{Introducción}

El libro de bautismo no solo es fuente importante para la historia del Sacramento. De manera indirecta, oblicua, facilita valiosa información acerca de las circunstancias de un parto. Proponemos en las páginas siguientes analizar las implicaciones de esta afirmación. Para ello nos basaremos en libros de bautismo de las primeras décadas del siglo XVII. Es una época en que se ven importantes cambios en el modo de controlar y de dar constancia del bautismo en los registros parroquiales; entre ellos figura la práctica de incluir referencias a los bautismos de urgencia, que solían administrarse poco después del nacimiento o incluso durante el mismo parto.

Para una historia social y cultural del nacimiento humano estas referencias pueden ser aprovechadas de tres maneras. Primero, se prestan a un estudio cuantitativo y permiten elaborar estadísticas sobre la frecuencia de los bautismos con agua de socorro y la cuota proporcional de los bautismos dados por emergencia respecto a los que se celebraban en la iglesia, con presencia del cura, ceremonia completa y fiesta. Segundo, suministran nombres de profesionales del campo de la obstetricia, en concreto nombres de comadronas. Cotejando estos nombres con otros documentos del periodo se pueden recopilar nuevos datos para una historia de la profesión, los ámbitos de trabajo de sus representantes, su implicación en la vida de la corte o también en pleitos y conflictos familiares. Tercero, los libros de bautismo ofrecen información adicional sobre las circunstancias del parto allí donde el cura párroco no se limita a asentar el acto de bautizar de manera escueta y siguiendo la fórmula prevista. En estos casos, cada vez más frecuentes hacia mediados del siglo XVII, el oficiante adjunta un breve texto que, a modo de informe y testimonio, recoge las palabras de un diálogo o interrogatorio. Los interlocutores en 
estos diálogos suelen ser el mismo párroco y otra persona que responde a sus preguntas acerca del modo en que se dio el bautismo al poco rato de nacer el niño.

Las entradas en los libros de bautismo que se debatirán son como breves miradas sobre lo que podía haber pasado en una casa donde se estuvo de parto, sobre lo que se hacía cuando el nacimiento se torcía y cuando el niño o la madre se veían en peligro de muerte. Hacen referencia a actos y gestos, a palabras rituales que se pronunciaron o a las personas reunidas en el cuarto para asistir a la parturienta y para atender a la criatura. Contienen frecuentes alusiones a la mujer que solía dirigir el parto, a la "comadre", según se solía llamar a la matrona en la temprana Edad Moderna, sus competencias y responsabilidades, además del control que se ejercía sobre ella a través del control del Sacramento ${ }^{3}$.

El examen de estos aspectos se basará en datos obtenidos de los libros de bautismo de las parroquias de San Justo y Pastor y de San Pedro de Barajas ${ }^{4}$. Ambas pertenecen hoy a la Comunidad de Madrid y pueden servir como ejemplos de dos parroquias del siglo, la una mantenía estrechas relaciones con la corte ${ }^{5}$, la otra era centro espiritual de una pujante villa señorial que encauzaba el comercio de cereales hacia Madrid ${ }^{6}$. Se presentarán los resultados más significativos contrastándolos con otras fuentes de la época. También se han aprovechado las múltiples referencias a bautismos de urgencia dispersos en publicaciones de temática áurea de diversa índole, entre ellas biografías de poetas y pintores, estudios monográficos sobre la historia de determinadas parroquias o también de la vida cortesana del siglo. Estos datos se relacionaron con estudios ya publicados que se dedican a la historia social y cultural del nacimiento y de la primerísima infancia.

Todo esto se ha hecho con la esperanza de que los datos manejados sirvan para proponer algunas tendencias, para formular hipótesis fundadas y para animar estudios que avancen y profundicen lo que se inicia aquí. Para ello se señalarán posibles perspectivas de investigación y posibles nexos entre la historia del sacramento y la historia social de la procreación en general.

\footnotetext{
2 "Llamamos comadre a la que ayuda a parir, que cura de la madre, y de la criatura. Esta por otro nombre se llama partera". Covarrubias Orozco, Sebastián de, Tesoro de la Lengua Castellana o Española, Madrid, Luis Sánchez, 1611, fols. 225v-226r.

${ }^{3}$ El estudio se sitúa, pues, en la línea de investigación iniciada entre otros por: García Martínez, Manuel Jesús et al., "La Administración del Bautismo de Urgencia. Una función tradicional de matronas", en Matronas Hoy, 4 (1994), pp. 47-53. Carmona-González, Inmaculada y María Soledad Saiz Puente, "El bautismo de urgencia, función tradicional del las matronas", en Matronas profesión, 4 (2009), pp. 18-19.

${ }^{4}$ Los libros de bautismo de San Justo y Pastor y de San Pedro de Barajas se conservan en el Archivo Histórico Diocesano de Madrid. Fueron sometidos a lecturas intensas durante una estancia de investigación en el verano de 2018. Estamos agradecidos a los funcionarios de la institución por su ayuda.

${ }^{5}$ San Justo fue una de las parroquias más antiguas de Madrid dado que ya aparece en el Fuero de 1202. Además, era la cuarta parroquia más poblada en el siglo XvII, Fayard, Janine, Les membres du Conseil de Castille à l'époque moderne (1621-1746), Genève-Paris, Droz, 1979, p. 445. La importancia de la parroquia también se puede deducir de su rango en las procesiones generales: "Orden que llevan las Iglesias Parroquiales en las Procesiones generales. En el primer lugar, Santiago. En el segundo, San Sebastián. En el tercero, San Justo y Pastor [...]”, Quintana, Gerónimo de, A la muy antigua, noble y coronada villa de Madrid. Historia de su antiguedad, nobleza y grandeza, Madrid, Imprenta del Reino, 1629, vol. 1, fol. 53v. Sobre Madrid y su población en el siglo XviI véase también Carbajo Isla, María F., La población de la villa de Madrid desde finales del siglo XVI hasta mediados del siglo XIX, Madrid, Siglo XXI, 1987; Pinto Crespo, Virgilio y Santos Madrazo Madrazo (dirs.), Madrid. Atlas histórico de la ciudad. Siglos IX-XIX, Madrid/Barcelona, Caja de Madrid/Lunwerg Editores, 1995 y Martorell Téllez-Girón, Ricardo, Aportaciones al estudio de la población de Madrid en el siglo XVII, Madrid, Estanislao Maestre, 1930. ${ }^{6}$ Ver Canosa Zamora, Elia, Historia de Barajas, Madrid, Ayuntamiento de Madrid, 2006.
} 
2. Bautismos de urgencia en dos parroquias del siglo XVII

\subsection{Reiterar el bautismo: ¿una práctica en aumento o un registro más completo y concienzudo?}

Los libros de bautismo aquí examinados hacen referencia al bautismo de socorro si se dan dos circunstancias. Primero, el cura párroco completa un bautismo ya efectuado tras el parto por los rituos secundarios y adicionales del exorcismo y de la unción con el santo crisma ${ }^{7}$. Segundo, el sacerdote reitera la administración del Sacramento porque hay dudas sobre la validez del primer intento. El Sacramento tiene su secuencia, su fórmula, su evolución correcta y solo una ejecución sin errores parecía garantizar el efecto deseado: que el alma del bautizado estuviera en condiciones de ser salvado, de gozar de vida eterna. Anotaba entonces el párroco que había bautizado sub conditione, es decir, había pronunciado la fórmula del bautismo en condicional: $S i$ non es baptizatus, ego te baptizo in nomine Patris, Filii et Spiritus sancti ${ }^{8}$. He aquí un segundo bautismo que sustituye al primero en caso de que este se hubiera impartido de manera errónea.

En ambos casos - exorcismo y santos óleos o bien bautismo sub conditione - el párroco asentaba en sus registros parroquiales un bautismo celebrado en la iglesia, pero dejaba constancia de que la ceremonia había sido antecedida por otra, que por regla general se había llevado a cabo en la casa en que había nacido el niño. Anotaba lo que añadió y posiblemente corrigió en la segunda ocasión, redactando una partida que según las Constituciones Sinodales de Toledo de 1622 debía tener la forma siguiente:

En el año del Señor, de N. a días del mes de N. nació un hijo, o hija, de N. y N. legítimamente casados, al cual por el peligro de la muerte bautizó N. partera aprobada, o N. parroquiano de N. o vezino de N. como de suso. [...]

En N. días del dicho mes, del dicho año, fue traído a la Iglesia parroquial de N. el dicho niño, o niña, al cual yo N. cura parroquial de ella, le di y administré las sacras ceremonias, preces, y oraciones, y le puse por nombre, N. ${ }^{9}$

La fórmula seguida habitualmente en los libros de bautismo analizados era semejante al siguiente ejemplo:

En la ciudad de Madrid en diez días del mes de diciembre de mil seiscientos y quarenta y cinco años yo el licenciado Ignacio Rosicler cura teniente de

\footnotetext{
${ }^{7}$ Ver Sánchez Diego, Héctor Fernando, Padrinazgo bautismal y parentesco espiritual: modelos y experiencias en la Cantabria moderna, tesis doctoral, Universidad de Cantabria, 2017, pp. 79-80.

${ }^{8}$ Ver por ejemplo Gebsattel, Lothar Anselm von, Ordo administrandi sacramenta aliaque munia pastoralia rite peragendi, Munich, Cancellaria Archiepiscopali, 1829, pp. 17-18.

${ }^{9}$ Las Constituciones Sinodales del Señor Don Fernando Cardenal Infante, Madrid, Bernardino de Guzmán, 1622, p. 64 .
} 
esta Iglesia parroquial de San Justo y Pastor de esta ciudad administré los exorcismos y catequismos a María por estar baptizada por mano del doctor Villareal presbítero por necesidad que tubo, hija de $[\ldots] .{ }^{10}$

También se utilizaba la fórmula "exorcisé al dicho infante; puse óleo y chrisma"11 o, en caso de que el cura dudara de la ejecución correcta del bautismo, "bapticé debajo de condición"12. Más adelante se darán ejemplos que indicarán el proceder de los eclesiásticos para averiguar la calidad del bautismo de socorro y darán una idea de los criterios que regían su actuación. Cabe, sin embargo, anteponer unas palabras acerca de la frecuencia del bautismo de urgencia en las dos parroquias aquí tratadas. Nos fundamos en un examen global de las primeras seis décadas del siglo XVII, además del cómputo de algunos años y meses, que se considerarán ejemplares y que en esta primera aproximación parecen suficientes para extraer tendencias generales. No se aspira a cumplir con las exigencias de un estudio rigurosamente cuantitativo.

En lo atinente a la parroquia de San Justo y Pastor, apenas se dan referencias al bautismo de urgencia entre 1616 y 1620: mientras que entre julio y diciembre de 1617 se anotaron siete bautismos de urgencia, de enero a julio de 1619 no se encuentra ni un solo caso entre 314 bautismos de urgencia ${ }^{13}$. De los siete bautismos de urgencia en la segunda mitad de 1617, el cura completó el Sacramento en seis casos con los exorcismos y en solo uno bautizó debajo de condición.

El número de bautismos extraordinarios, que se anotaron en los libros sacramentales de manera indirecta, aumentó a lo largo de los años veinte, aunque todavía quedaron bastantes meses sin que se diera ningún acto sacramental de emergencia, como demuestran las catas realizadas en los meses de febrero, julio y diciembre de 1623, de mayo y noviembre de 1624 y de enero y septiembre de $1627^{14}$.

En 1645, en cambio, se registró por lo menos un bautismo de emergencia cada mes. Y el número total fue alto: 68 de entre 470, es decir un 14,5 por ciento ${ }^{15}$. En 1653, en los meses de noviembre y diciembre se consignaron 84 bautismos, 15 de ellos son complementarios (exorcismos y santos óleos) o se administran sub conditione. Constituyen un 17,9 por ciento del total ${ }^{16}$. Los libros sacramentales de la villa de Barajas confirman las tendencias que vimos

\footnotetext{
${ }^{10}$ Archivo Histórico Diocesano de Madrid [en adelante, AHDM], Fondo parroquial de San Justo y Pastor, Libro 10 de Bautismos, Nº Prov. 992, 1.1.1643-17.4.1651, fol. 191v.

${ }^{11}$ AHDM, Fondo parroquial de la Iglesia colegial de San Pedro de la villa de Barajas, Libro 5 de Bautismos, 16601663 , fol. $6 \mathrm{v}$.

${ }^{12}$ AHDM, Fondo parroquial de San Justo y Pastor, Libro 10 de Bautismos, Nº Prov. 992, 1.1.1643-17.4.1651, fol. 172 r.

${ }^{13}$ AHDM, Fondo parroquial de San Justo y Pastor, Libro 6 de Bautismos, No Prov. 988, 10.4.1616-31.12.1621, fols. 74v, 77r, 84v, 88v, 95v, 96v, 98r.

${ }^{14}$ AHDM, Fondo parroquial de San Justo y Pastor, Libro 7 de Bautismos, No Prov. 989, 2.1.1622-28.12.1627.

${ }^{15}$ AHDM, Fondo parroquial de San Justo y Pastor, Libro 10 de Bautismos, No Prov. 992, 1.1.1643-17.4.1651, fols. $130 \mathrm{r}-131 \mathrm{r}, 132 \mathrm{r}, 133 \mathrm{v}, 135 \mathrm{v}, 136 \mathrm{v}-138 \mathrm{r}, 140 \mathrm{v}, 143 \mathrm{v}, 146 \mathrm{r}, 150 \mathrm{r}, 152 \mathrm{r}, 153 \mathrm{r}, 154 \mathrm{v}, 155 \mathrm{r}, 158 \mathrm{r}, 159 \mathrm{r}-160 \mathrm{r}, 161 \mathrm{r}-\mathrm{v}$, $163 \mathrm{r}, 165 \mathrm{r}-166 \mathrm{v}, 167 \mathrm{v}-168 \mathrm{r}, 169 \mathrm{r}-170 \mathrm{r}, 172 \mathrm{v}, 174 \mathrm{v}, 176 \mathrm{r}, 178 \mathrm{r}-179 \mathrm{v}, 180 \mathrm{v}-181 \mathrm{r}, 182 \mathrm{v}, 183 \mathrm{r}, 185 \mathrm{v}-186 \mathrm{r}, 187 \mathrm{r}-188 \mathrm{r}$, 190r, 191r-v, 196r.

${ }^{16}$ AHDM, Fondo parroquial de San Justo y Pastor, Libro 11 de Bautismos, No Prov. 993, tomo II, 19.4.16512.5.1659, fols. $159 \mathrm{v}-168 \mathrm{r}$.
} 
en la parroquia del centro histórico de Madrid. Aumentan los bautismos condicionales a lo largo del siglo XVII, y en la década de 1660 conforman una parte considerable de todos los bautismos. En diciembre de 1660 son uno de entre siete, en marzo de 1661 uno de dos. En 1663 figuran 25 niños bautizados, cinco de ellos se registran como sometidos al ritual católico por segunda $\mathrm{vez}^{17}$.

\section{2. ¿Por qué se asientan más bautismos de urgencia?}

Durante la primera mitad del siglo XVII se percibe un aumento continuo de las referencias a bautismos de urgencia. Al iniciarse la centuria, apenas aparecen noticias sobre este tipo de bautismo precario. En cambio, hacia mediados del siglo no hay mes sin alusión al agua de socorro, y el número es considerable: hasta una sexta parte en algunos meses. ¿A qué se podría deber esta diferencia?

Primero, pudo haber aumentado el número de niños que nacieron con una constitución que indicaba la inminencia de la muerte. Tal vez influyera este factor y probablemente en los años de escasez, guerras y peste nacieron más niños sin fuerza para $\operatorname{vivir}^{18}$, mas no creemos que fuera el elemento "decisivo" para explicar el cambio en el contenido de las partidas de bautismo. Segundo, las personas que asistieron al parto cambiaron de criterio referente a lo que consideraron un parto con peligro de muerte. Esto incrementó el número de bautismos por necesidad. Hay indicios de que tal fuera el caso y volveremos sobre este punto cuando examinemos el papel de las comadres.

Pero probablemente se deba asignar más peso a un tercer factor que hiciera aumentar las cifras con independencia del número real de niños bautizados por necesidad: los esfuerzos de la Iglesia tanto por reglamentar el rito como por controlar su correcta documentación en los libros de bautismo ${ }^{19}$. Los escritos que la época dedica al tema lo señalan con claridad. Así, por ejemplo, el Concilio de Trento aboga por un bautismo rápido e insiste en la fórmula correcta a la hora de administrar el bautismo ${ }^{20}$. Eso está reflejado en textos publicados como consecuencia del Concilio; el Ritual Romano, instaurado por el papa Pablo V en 1614, propaga la visión apostólica del rito ${ }^{21}$. El Catecismo romano compuesto por decreto del sagrado Concilio

\footnotetext{
${ }_{17}^{17}$ AHDM, Fondo parroquial de la Iglesia colegial de San Pedro de la villa de Barajas, Libro 5 de Bautismos, 16601663 , fols. $6 \mathrm{v}-38 \mathrm{r}$.

${ }^{18}$ Ver por ejemplo Carretero Melo, Antonio, “Onomástica y demografía. Apuntes metodológicos”, en Nouvelle revue d'onomastique, 39-40 (2002), pp. 222-223.

${ }^{19}$ Rueda Fernández afirma que "[f]ue, en efecto, a partir de 1650-1670 cuando las partidas comenzarían a enriquecerse en detalles, los libros a uniformizarse interior y exteriormente, y a surgir una preocupación por todo cuanto atañía a la autenticidad, la integridad, el control y la conservación de los mismos", Rueda Fernández, José C., "Los registros parroquiales en Castilla. Notas sobre su implantación, desarrollo y reglamentación en la ciudad y diócesis de Zamora (siglos XVI y XVII)", en Studia historica. Historia moderna, 8 (1990), p. 11.

${ }^{20}$ Ver Gélis, Jacques, Les enfants des limbes. Mort-nés et parents dans l'Europe chrétienne, s.l. [París], Audibert, 2006, p. 176; p. 42: Mantiene Gélis que fue fácil imponer la medida, ya que el pueblo temía las almas en pena de criaturas no bautizadas, pp. 180-181.

${ }^{21}$ Ver Rueda Fernández, José C., "Los registros parroquiales en Castilla... op. cit., pp. 1-13 y passim. Rituale Romanum Pauli V. Pont. Max. iussu editum. Cum Coniurationibus ad fugandas tempestates, \& Benedictione
} 
Tridentino dispone que toda persona puede bautizar en caso de necesidad sin ceremonia solemne, también pueden administrar el agua de socorro judíos, "infieles" o "herejes", con tal de que "propongan hacer aquello, que la Iglesia Católica hace en la administración de este Sacramento" 22 . Sin embargo, establece una clara jerarquía: el más señalado para bautizar sería un sacerdote, a falta de tal puede oficiar un clérigo; donde no haya cerca ningún clérigo es preferible que bautice un hombre antes que una mujer. Sin embargo, se estipula que "las parteras que están acostumbradas a bautizar, no son reprensibles por ejercer alguna vez este oficio en presencia de algún hombre poco inteligente en el modo de administrar este Sacramento"23. El oficio obstétrico, según se ve, prevalece sobre el género.

Incurren en "grave culpa" las personas que esperan "más tiempo del que la necesidad requiere" antes de bautizar al niño ${ }^{24}$. Los autores del catecismo también se pronuncian sobre el bautismo debajo de condición. Afirman que "como dice San Agustin, «no podemos volver al vientre de la Madre», así también una sola es la regeneración espiritual, y por consiguiente nunca se puede reiterar el Bautismo". Solo es lícita la repetición cuando hay duda sobre la validez y después de una diligente averiguación ${ }^{25}$.

Además, la Iglesia postrentina insiste cada vez más en la correcta documentación de los bautismos y de los bautismos de urgencia que pudieran haber antecedido al rito solemne en la iglesia parroquial ${ }^{26}$, siendo las visitas pastorales su mayor instrumento de control $^{27}$. Es muy probable que este cambio de postura explique la gran diferencia que hallamos entre las primeras décadas del siglo XVII y las décadas centrales del siglo con respecto al número de bautismos de emergencia anotados.

Así, el aumento de testimonios no necesariamente corresponde a un aumento real de los bautismos de urgencia. Probablemente el índice de bautismos fuera alto ya al comienzo del siglo. De haberse consignado, probablemente las cifras no hubieran diferido tanto de aquellas que arrojan las décadas posteriores.

\footnotetext{
Aquae, quae fit in Vigilia Ephiphaniae, \& alijs, Venetiis, Benedictum Milochum, 1679, pp. 7-18.

${ }^{22}$ Catecismo romano compuesto por decreto del sagrado Concilio Tridentino: Para los párrocos de toda la iglesia y publicado por san Pio V. Traducido del latín al castellano, según el Decreto del mismo Sagrado Concilio, por don Lorenzo Agustín de Manterola, tomo I, Pamplona, en las oficinas de Benito Cosculluela y Josef Longás, 1780 , parte II, capítulo II, p. 179. Catechismus romanus ex Decreto Concilii Tridentini, ad parochos, Pii V. Pont. Max. iussu editus, Romae, Paulum Manutium, 1566, p. 190. Rituale Romanum... op. cit., p. 8.

${ }^{23}$ Catecismo romano... op. cit., p. 180. Catechismus romanus... op. cit., p. 191.

${ }^{24}$ Catecismo romano... op. cit., p. 185. Catechismus romanus... op. cit., pp. 196-197.

${ }^{25}$ Catecismo romano... op. cit., pp. 199-200. Catechismus romanus... op. cit., pp. 210-211. Rituale Romanum... op. cit., p. 7.

${ }^{26}$ Así lo disponen Las Constituciones Sinodales... op. cit., p. 64.

${ }^{27}$ Ver Fernández García, Matías, Parroquias madrileñas de San Martín y San Pedro el Real: algunos personajes de su archivo, Madrid, Caparrós editores, 2004, p. 13: "Las autoridades eclesiásticas, por medio de sus visitadores, conscientes de tales carencias de datos de identificación, se ocuparon de recordar a los párrocos de las iglesias el modo de escribir las partidas, especialmente las de bautismo. En sus mandatos se solía urgir el cumplimiento de lo ordenado en el Concilio de Trento, amenazando con censuras o pena pecuniaria a quienes no lo cumplieran". Ver también Fonseca Montes, Josué, Religión, muerte y sexualidad en los siglos XVI-XVIII: El caso de Cantabria, Santander, Ed. Universidad de Cantabria, 2014, p. 238: "En el curso de las inspecciones pastorales o archidiaconales, el visitador jamás dejaba de interrogar [a la comadre] al respecto. [...] La consulta de los registros parroquiales franceses revela que las negligencias en lo que concierne a la administración del bautismo fueron cada vez más escasas a partir de finales del siglo XVII. Igualmente se enfatizó la seriedad de la ceremonia sacramental, excluyendo a los padrinos y madrinas que no hubieran cumplido sus obligaciones pascuales".
} 
Es más: se debe señalar una peculiaridad que hace que más allá de las cifras que podemos manejar siempre siga abriendose un terreno de grandes incertidumbres. Ello es que los libros de las parroquias de Madrid no registraron los bautismos de niños que morían al poco tiempo y cuyo primer bautismo no fue completado o confirmado en la pila bautismal; no se solían asentar los niños que se bautizaron y murieron luego. Las referencias a estos casos sí se dieron en España pero parece que fueron escasísimas: así, en la parroquia de Alameda del Valle, el presbítero afirmó en el año 1611 que un niño se había bautizado en casa por necesidad, que lo bautizó un hombre, que murió luego y que no hubo padrino ${ }^{28}$. En 1645, el cura de Bocacara señaló que la comadre había bautizado a dos niños gemelos, María y Francisco, en casa, y por la gran necesidad, y que María murió a los cuatro días ${ }^{29}$. El mismo cura en 1648 bautizó a un recién nacido en casa y acabó indicando que murió el 22 de diciembre, 15 días después del bautismo de urgencia ${ }^{30}$. En vista de los documentos hasta aquí examinados parece ser que se tratara en esos casos de un afán registrador excepcional para la época ${ }^{31}$.

Se puede afirmar, empero, que el porcentaje de niños que se perciben en un estado muy crítico al nacer o poco antes de nacer es elevado. Por tanto la posibilidad de que se deba proceder al bautismo de manera expeditiva siempre se debe haber tenido en cuenta. Esa posibilidad habrá influido en los preparativos del parto, habrá formado parte de las expectativas de todos los implicados. Constituía uno de los escenarios concebibles por la parturienta, la comadre y la familia de los padres. Tanto a los hombres de la Iglesia como a los legos les preocupaba que ningún niño muriera sin bautismo y que su alma no quedara relegada a este terreno triste -mal definido teológicamente ${ }^{32}$ pero poderoso en sus efectos culturales - que fue el limbus puerorum $^{33}$.

\footnotetext{
${ }^{28}$ AHDM, Fondo parroquial de Alameda del Valle, Libro 1 de Bautismos, 1555-1667, fol. 106v. Ver también Lelaidier, Isabel, "Matrimonios y bautismos en el Puerto de Santa María durante la primera mitad del siglo XVII", en Revista de Historia de El Puerto, 13 (1994), pp. 43-67. Los resultados que presenta la autora concuerdan con los nuestros: ningún bautismo de urgencia registrado entre 1600 y 1622, luego nada menos que 200 para los años 1622-1630. Parece ser que se registraron todos los actos sacramentales postnatales, pero la historiadora no lo deja del todo claro.

${ }^{29}$ Archivo Diocesano de Ciudad Rodrigo, Libro de Bautismos, Sancti Spiritus, Parroquia Espíritu Santo, No 492, 1639-1749, fol. 53v.

${ }^{30}$ Ibídem, fols. 56r-v.

${ }^{31}$ Ver México Gallardo-Hurtado, Georgina Yólotl y Lizbeth Margarita Osornio-García, "Los archivos parroquiales de la Villa de Toluca, 1684-1760", en Papeles de población, vol. 15, 60 (2009), p. 238: "La omisión o registro incompleto puede deberse al no registro de los decesos de niños bautizados de urgencia en su casa, ya que casi no hubo registros de este tipo". Sobre el desarrollo histórico, las prácticas divergentes y la relativa fiabilidad de los libros sacramentales en cuanto al número de niños muertos a muy corta edad ver también Brel Cachón, María Pilar, "Comparación de los libros parroquiales y de los registros civiles", en Revista de Demografía Histórica, vol. 17, 2 (1999), pp. 107-109. Gómez-Cabrero Ortiz, Ángel, "Sociedad, familia y fecundidad en Mocejón (1660-1719): Una reconstrucción de familias", en Revista de Demografia Histórica, vol. 9, 1 (1991), pp. 67-68. Sobre la falta de documentación y nuevos enfoques metodológicos ver también Carretero Melo, Onomástica... op. cit., p. 221. ${ }^{32}$ Ver Gélis, Jacques, Les enfants ... op. cit., pp. 169-208.

${ }^{33}$ Para los matices y diferentes fases del debate remitimos a los trabajos de Jacques Gélis y de Franceschini, Chiara, Storia del limbo, Milán, Feltrinelli, 2017. Ver también Dimas Serpi, Calaritano, Tratado del purgatorio contra Lutero, y otros herejes... Barcelona, Jaime Cendrat, 1604, pp. 54-56, 100: El Concilio de Trento, afirma Dimas Serpi, no ha determinado nada que sea definitivo; es posible que Dios se apiade de los inocentes no bautizados. Estamos preparando un estudio que examinará las imágenes colectivas y los ecos literarios —El gran teatro del mundo de Calderón, con su niño, que nace muerto, entre otros- que suscitó el tema.
} 
Por lo tanto, toda persona que dirigía un parto asumía autoridad y responsabilidad. Entre estas personas destaca la comadre. Los libros de bautismo dan dos pistas que permiten un acercamiento a su actuación. La primera se abre por medio de los nombres propios incluidos en las partidas; la segunda, por lo que se cuenta acerca de sus acciones y decisiones. Ambos aspectos se tratarán por separado en lo que sigue.

\subsection{Perfiles de comadres bautizantes}

Conforme aumenta el afán por tomar nota del bautismo de urgencia, un buen número de partidas incluye los nombres y los oficios del primer bautizante. Entre ellos, el grupo que prevalece en cuanto al número de menciones es el gremio de las comadronas. Algunas veces se da el nombre completo de la comadre, y otras el apodo o sobrenombre por el cual era llamada. También hay partidas que se contentan con afirmar que bautizó una representante del oficio. Valga un ejemplo: según las indicaciones de los libros de bautismo de San Justo y Pastor para el año 1645, de 68 bautismos de socorro, 17 fueron dados por la comadrona; en 14 ocasiones se registró el nombre. Así, una tal Francisca Pérez figura tres veces, la "comadre de Cuenca" dos, Fabiana de Anaraste [lectura difícil del apellido], Juana Baptista, Manuela, María Ibañez, María Ruiz, Enzinas, César, Aguado e Inés de Ayala una vez cada una. Once nombres de comadronas, en suma, para 14 bautismos a los que se pueden agregar tres referencias a una "comadre" o una "comadre aprobada" 34 . Por medio de una investigación exhaustiva se podría elaborar un elenco biográfico de las comadres activas en la Corte de Madrid o en otras partes de España en tiempos de su esplendor y decadencia ${ }^{35}$, conectando los nombres de esta lista con otros escritos de la época, facilitando piezas para la reconstrucción de caminos biográficos y sus variadas peripecias. Prueba de ello son los resultados ya arrojados por una breve búsqueda biográfica en torno a los nombres identificados para el año 1645. Dos de ellos se pueden insertar en una red de datos más amplia, de modo que se atisban vínculos familiares, relaciones sostenidas por el parentesco, por la lealtad o también por la involucración común en acciones fraudulentas y criminales; se entreven éxitos profesionales y carreras torcidas por la tentación del soborno y del enriquecimiento delictivo. Las comadres en cuestión son Inés Ramírez de Ayala y la "comadre de Cuenca", epíteto que muy probablemente solía usarse para referirse a una tal Catalina de Cuenca.

\footnotetext{
${ }^{34}$ AHDM, Fondo parroquial de San Justo y Pastor, Libro 10 de Bautismos, No Prov. 992, 1.1.1643-17.4.1651, fols. 130-131r, 132r, 133v, 136v, 146r, 153r, 155r, 159r-v, 166v, 176r, 178r, 180v-181r.

${ }^{35}$ Con esto se añadirán datos a la lista de nombres proporcionada por De Carlos Varona, María Cruz, Nacer en palacio. El ritual del nacimiento en la corte de los Austrias, Madrid, Centro de Estudios Europa Hispánica, Madrid, 2018, pp. 138-141. Vale la pena revisar desde este ángulo las biografías y redes familiares de personajes importantes del siglo. Así, por ejemplo, el 9 de marzo de 1646 se bautizó a Julián Antonio, hijo de Francisca Velázquez de Silva, hermana del famoso pintor. El cura completó un bautismo "por necesidad" administrado por la comadre Ana la Pulida. Ver Méndez Rodríguez, Luis, "Entre la vida y la muerte. Nuevas aportaciones documentales sobre Velázquez en Sevilla", en Archivo español de arte, 288 (1999), p. 539.
} 
Inés de Ayala atendió a las parturientas de la Casa de Austria, en palacio y con título oficial a partir de $1638^{36}$. Trajo al mundo a María Teresa de Austria, hija de Isabel de Borbón, y asistió a Mariana de Austria, segunda mujer de Felipe IV, en los nacimientos — entre otros - de Margarita María Teresa, Felipe Próspero, Fernando Tomás y del futuro rey Carlos II. Inés de Ayala mantuvo excelentes relaciones con una protagonista de la vida religiosa de la corte, la afamada beata Mariana de Jesús, cuyo consejo tuvo en alta estima cuando se trataba de atender un parto difícil o de superar sus propias cuitas de parturienta y madre. Cuando murió Inés de Ayala en el año 1663, dejó una importante fortuna y a sus hijos colocados en prestigiosos puestos palaciegos. Su fama fue internacional y duradera, pues el embajador austriaco Franz Eusebius von Pötting la menciona en una carta dirigida al emperador Leopoldo I en $1672^{37}$. El libro de bautismo del año 1645 la señala ejerciendo su oficio en una casa acomodada de la parroquia de San Justo y Pastor; es la casa de su hijo, quien ocupa un puesto de funcionario en palacio, la niña que se bautiza por necesidad es la propia nieta de la matrona. Es muy probable que en esa ocasión fueran razones familiares las que llevaran a Inés de Ayala a trabajar en una casa de la villa. Sin embargo, no era la primera vez que ejercía su profesión en la parroquia. En el 1629 había parteado a la madre de don Juan José de Austria, hijo del rey, en una casa particular, y había figurado como madrina en el bautismo ${ }^{38}$.

El caso de la comadre de Cuenca da fe de los posibles nexos entre el parto, la transmisión del patrimonio familiar y la acción jurídica, que podían acarrear manipulaciones fraudulentas. Como se ha observado, Catalina de Cuenca figura dos veces como bautizante en San Justo y Pastor en el año 1645. Luego, en algún momento, ayudó a crear una falsa apariencia de maternidad al dirigir una ficticia escena de parto con la introducción y presentación pública de un recién nacido que había sido dado a luz por otra mujer. Fue cómplice, pues, en una suposición de parto, delito que hoy se adscribe a la categoría de los delitos contra las relaciones familiares $^{39}$. Como fondo del asunto los cronistas indican conflictos entre parientes cercanos y el intento de usurpar un mayorazgo recurriendo a un fraude de dimensiones considerables, pues se trata de nada menos que de escamotearle los padres naturales a un niño, de asignarle otros y de perjudicar a todos aquellos que pudieran aspirar a un patrimonio. Según los testimonios del periodo, Catalina de Cuenca fue descubierta y condenada a 200 azotes y a galera perpetua. Pero al poco tiempo de nacer el príncipe Felipe el Próspero el 28 de noviembre de 1657 "soltaron a todas las mujeres que estaban en la Galera", y entre ellas la "comadre llamada la Cuenca,

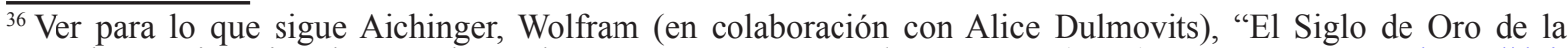
comadre: testimonios de Inés de Ayala", en Memoria y Civilización, 21 (2018), pp. 11-41. DOI: https://doi. org/10.15581/001.21.026

37 Ibídem, pp. 12, 32.

${ }^{38}$ Ibídem, pp. 17-19.

${ }^{39}$ Carracedo Falagán, Carmen, "Tratamiento jurídico-penal de la suposición de parto o parto fingido en la Edad Moderna", en García Galán, Sonia et al. (eds.), Nacimientos bajo control. El parto en las edades Moderna y Contemporánea, Gijón, Trea, 2014, pp. 67-73.
} 
condenada en vida por haber supuesto un parto falso en perjuicio de un mayorazgo" ${ }^{40}$. Es un ejemplo, tal vez extraordinario en sus particularidades, de cómo los libros de bautismo y los nombres contenidos en ellos, pueden completar mosaicos biográficos y volver más densa la red de datos sobre lo que podía estar en juego en un parto durante el Siglo de Oro.

Si no es la comadre quien bautiza, suele oficiar un hombre, y la mayoría de las veces un hombre con título universitario o función eclesiástica. También aparecen hombres con cargos en algún hospital o en alguna institución caritativa ${ }^{41}$.

Debemos apuntar, por último, que un buen número de niños figuran como hijos de padres desconocidos. No les dedicamos un estudio pormenorizado, por lo que en esta ocasión no podemos calibrar el porcentaje que componen entre todos los bautizos. Algunos casos, empero, permiten vislumbrar un guión que se repetía: un niño es abandonado en algún lugar, alguien lo encuentra y lo bautiza de necesidad, y luego hace de padrino cuando se completa el ritual por el sacerdote de la parroquia. Esto fue lo que ocurrió con la criatura que en noviembre de 1653 recibió el nombre de Carlos y que había sido bautizado "de socorro" por Francisco de Montealegre. Fue este tal Montealegre quien lo sostuvo en sus brazos para el exorcismo y los santos óleos ${ }^{42}$.

\section{Bautizar interrogando}

No abundan las fuentes que contengan una descripción detallada de la organización y asistencia a un parto; lo impedía el decoro. Además, los protagonistas - femeninos en su mayoría - no pertenecían a la clase de personas que solía dejar testimonios escritos de sus vivencias. Ahora bien, se ha podido ver que la gran mayoría de las partidas de bautismo se contenta con la fórmula, con el registro de la administración del Sacramento, además de los nombres y fechas relacionados con el acontecimiento. Son datos de enorme interés para los estudios demográficos, onomásticos o de las relaciones de parentesco ${ }^{43}$, pero poco reveladores en lo que a la escena del parto se refiere.

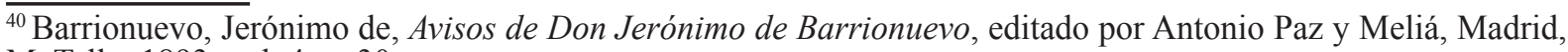
M. Tello, 1893, vol. 4, p. 30.

${ }^{41}$ Así por ejemplo, AHDM, Fondo parroquial de San Justo y Pastor, Libro 11 de Bautismos, No Prov. 993, tomo II, 19.4.1651-2.5.1659, fols. 6v, 8v, 159v, 160r, 162r, 163v, 166v, 167r, 168r. Ver también AHDM, Fondo parroquial de San Justo y Pastor, Libro 10 de Bautismos, No Prov. 992, 1.1.1643-17.4.1651, fols. 150r, 152r, 169r, 183r. ${ }^{4}$ Ibídem, fol. 162v. Ver también, con casos del siglo xviII, Tarifa Fernández, Adela, "Los niños expósitos de Úbeda (Jaén) y Sepúlveda (Segovia) en el Antiguo Régimen: las obras pías de San José y San Cristóbal”, en Campos y Fernández Sevilla, Francisco Javier (coord.), La Iglesia española y las instituciones de caridad. Actas del Simposium, San Lorenzo de El Escorial, Ediciones Escurialenses, 2006, p. 215.

${ }^{43}$ Ver Ansón Calvo, María del Carmen, "Los archivos parroquiales como fuente para la demografía y la genealogía", en Memoria ecclesiae, 9 (1996), pp. 9-45. García Pérez, María Sandra, "Apuntes sobre los archivos parroquiales en España", en Biblios, 33-34 (2009), pp. 3-5.
} 
Sin embargo, intercalados entre tanta repetición protocolaria, despuntan algunos pasajes de más enjundia, más extensos, descriptivos y enfocados en los pormenores de un caso particular. En estos pasajes el cura párroco da razón de sus propias averiguaciones, llevadas a cabo junto a la pila bautismal. Solían estar la abuela, la comadre, el padre y los padrinos del niño. Preguntados por el oficiante, alguien que estuviera presente también en el parto describía la conducción de un bautismo de emergencia, administrado justo después de que naciera el niño o incluso antes de que hubiera nacido por completo. Suelen asumir este papel de testigo informante o la comadre o la abuela. A continuación examinaremos cuatro de estos casos extraordinarios. Constituyen testimonios raros en cuanto a su extensión y a la cantidad de detalles que dan ${ }^{44}$, pero bien se pueden tener por ilustrativos en cuanto a las actitudes que reflejan. Provienen todos de la parroquia de San Pedro de Barajas.

El primer caso se dio el primero de diciembre de 1660, cuando se bautizó a un tal Francisco Andrés, hijo de Juan de Bustamante y de doña Clara Díaz. El presbítero, cuyo nombre es Rafael Durón, anota que:

[...] antes de exorcisar pregunté a María Sanz, comadre de esta villa y vecina della en qué parte del cuerpo bautizó al infante que traía a bautizar por haber dicho tenía agua [sic], la cual dijo que por estar dudosa del parto, habiendo sacado la cabeza, el infante se bautizó en ella y le dijo las palabras que para el tal bautismo se requieren, con intención de hacer lo que la Iglesia manda, y oído y entendido lo susodicho exorcisé al dicho infante y hice los demás exorcismos que la Iglesia dispone; puse óleo y crisma; al cual niño le fue puesto por nombre Francisco Andrés el cual nació a ocho días de mes de noviembre. [...] Fueron sus padrinos para los dichos exorcismos y óleo y crisma el Sr. D. Francisco Bernardo Muñoz de Luna, capellán mayor y cura propio de dicha iglesia y Da. Francisca Mencía, abuela del dicho niño, vecinos de dicha villa. ${ }^{45}$

El 28 de diciembre de 1661 tiene lugar el bautismo solemne de Francisca María, nacida el 20 de diciembre. El cura párroco hace el exorcismo y:

[...] yendo a la pila bautismal para el efecto de bautizarla pregunté a la comadre desta villa si tenía agua y en qué parte del cuerpo se la había echado y qué palabras dijo y qué agua echó. Dijo y respondió que la había bautizado con agua natural y que se la había echado en un brazo y que había dicho las palabras que usa la iglesia y que dijo "yo te bautizo en el nombre del padre, y del hijo y del espíritu santo" y habiendo dicho lo susodicho y que el bautismo no había sido en la cabeza, la bauticé debajo de condición diciendo Francisca

\footnotetext{
${ }^{44}$ Una partida bastante elocuente, que data del libro de bautismos de Melilla, año 1694, la reproduce Reder Gadow, Marion, "IA-B: Historia económica - Historia social", en Bernardo Ares, José Manuel de et al., Recuperar la historia, recuperar la memoria: edición crítica de textos para el aprendizaje de historia moderna, Córdoba, Servicio de Publicaciones Universidad de Córdoba, 2007, p. 60.

${ }^{45}$ AHDM, Fondo parroquial de la Iglesia colegial de San Pedro de la villa de Barajas, Libro 5 de Bautismos, 16601663 , fol. $6 \mathrm{v}$.
} 
María si non es baptizata ego te baptizo in nomine patris et filii et espiritu santo [sic] los cuales nombres deferidos [sic] se le pusieron por nombres. ${ }^{46}$

De la misma entrada se puede extraer el nombre de la madrina, una tal Ana Sanz; de nuevo es la abuela a quien le toca este papel.

El 17 de marzo de 1661, se otorgaron el Sacramento y el nombre de Antonio al hijo de Antonio de Vargas y María Melendro. Nació el día 2 de marzo. Consta en el libro de bautismo que:

[...] queriendo echarle agua del bautismo pregunté a doña Juliana Vázquez, su abuela, si le habían echado agua, la cual respondió que una mujer que trujeron de fuera para que sirviese de comadre viendo el peligro con que nació el dicho niño de la vida le echó agua, pero que estaba dudosa como había dicho las palabras y que así le echase agua, oyendolo referido le bauticé con condición diciendo "Antonio si non est baptizatus [...]". ${ }^{47}$

El 26 de febrero de 1663 se bautizó un bebé de nombre Antonio Ignacio. Su abuela, Juana Vázquez, depuso lo siguiente: el niño nació en su casa, el bautismo fue dado por el que es "su yerno pero no marido de la madre del niño". Vertió este el agua en la cabeza del niño. Juana Vázquez no se acordaba de las palabras que se dijeron, ni si había “intención” de dar el Sacramento. El cura repitió el bautismo sub conditione y confirmó el nombre que el niño ya había recibido al nacer en casa ${ }^{48}$.

Son cuatro casos con notables analogías, similitudes y diferencias. En el primer ejemplo, el bautismo solemne de Francisco Andrés, se consigna el testimonio de la abuela del recién nacido. Lo que refiere sobre el bautismo de socorro administrado por la comadrona "oficial" del lugar satisface al párroco. Este se contenta con completar el primer bautismo con el exorcismo y la unción de la cabeza del niño. En cuanto al bautismo de Francisca María, se registra el testimonio de la comadre de la villa. Esta refiere un bautismo de urgencia dada por ella misma, durante el cual había vertido el agua bautismal sobre un brazo de la niña, lo cual motiva al párroco a confirmar el Sacramento sub conditione ${ }^{49}$. En el bautismo de Antonio, hijo de María Melendro, habla la abuela del niño y testifica la acción bautizante de una comadre sin título oficial. No puede asegurar la correcta ejecución del rito. Por otra parte, en el documento sobre el bautismo de Antonio Ignacio, celebrado en 1663, no aparece la comadre; en cambio se percibe el protagonismo de la abuela materna y de un pariente cercano del niño. Este deudo masculino dirige el Sacramento. Sin embargo, su proceder no se tiene por fiable en cuanto a lo que ordena la Iglesia. En todos los casos salvo el primero se bautiza sub conditione, pues el sacerdote

\footnotetext{
${ }^{46}$ Ibidem, fol. $19 \mathrm{v}$.

${ }^{47}$ Ibídem, fol. 9 r.

${ }^{48}$ Ibidem, fol. 35 r.

${ }^{49}$ Actuó en acuerdo con la opinión teológica predominante en la época. Ver Mota, Francisco de la, Compendio de la suma añadida del R. P. Fr. Martin de Torrecilla, Madrid, Antonio Román, 1698, p. 595, donde se debate la cuestión.
} 
alberga serias dudas sobre la validez del bautismo de socorro. En los dos primeros testimonios queda patente que el niño ya se bautizó antes de que hubiera nacido del todo ${ }^{50}$.

Estos diálogos, por breves que sean, presentan recurrencias significativas: el destacado papel de la comadre, la frecuente mención de la abuela en diferentes papeles y acciones o la presencia discreta pero notable de parientes masculinos, con lo que facilitan indicios importantes para una historia social y cultural del parto. Confirman o corrigen lo que ya sabemos, y también añaden detalles importantes. Hacen mención al lugar del nacimiento, al valor de objetos y sustancias que ahí se tienen preparados, a la configuración de las personas presentes y al reparto de tareas que se da entre ellos. De manera indirecta hablan de la autoridad que ejercen las personas involucradas y de los riesgos y responsabilidades que asumen. Cada uno de estos aspectos merece ser debatido brevemente.

\subsection{La casa de la abuela}

El bautismo de emergencia se administra en la casa en la que nace el niño. La afirmación no es tan trivial como podría parecer porque no siempre fue así. No todos los niños nacen en su casa, y no todos los niños que precisan el agua de socorro lo reciben en su casa natal. Los niños expósitos, por ejemplo, con frecuencia se bautizaron de urgencia en los hospitales, casas cuna $\mathrm{u}$ hogares de particulares en que fueron acogidos ${ }^{51}$. En caso de grave peligro de muerte ya se despachó el Sacramento en el mismo lugar en que fueron encontrados ${ }^{52}$.

Los niños de Barajas, empero, suelen nacer en familia, en el sentido amplio del término, puesto que la casa de la abuela también fue un posible lugar de nacimiento. Esta casa, por lo visto, se ha preparado y acomodado para el acontecimiento ${ }^{53}$. La abuela hace de anfitriona de parto y este papel fue uno de varios roles que le tocaba desempeñar en la gestación de un embarazo, del parto y del puerperio. A la luz de otros documentos podemos suponer que no es casualidad que fuera la abuela materna (y no la paterna) la que respondía en febrero de 1663. En pueblos rurales de Castilla y Extremadura el parto siguió siendo asunto parcialmente matrilocal

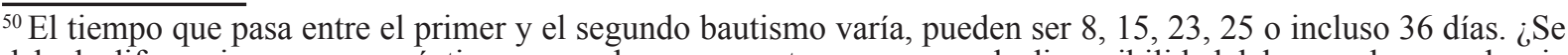
debe la diferencia a razones prácticas que no hacen a nuestro caso, como la disponibilidad del cura o la precedencia de otras fiestas o ceremonias en la iglesia? ¿O tenía que ver con la salud del niño? ¿Se esperaba para ver si el niño de verdad "salía adelante" para no montar una fiesta que en el momento menos esperado podía ensombrecerse con la muerte del niño que había nacido débil? ¿O fue al revés? ¿Tenían más prisa en re-bautizar un niño que seguía en peligro para que no cupiera ninguna duda de la validez del Sacramento?

${ }^{51}$ Sobre la Inclusa de Madrid y los bautismos de expósitos en la parroquia de San Ginés véase Espina Pérez, Pedro, Historia de la Inclusa de Madrid, vista a través de los artículos y trabajos históricos años 1400-2000, Madrid, Defensor del Menor en la Comunidad de Madrid, 2005.

${ }^{52}$ Ver, con casos del siglo xVIII, Tarifa Fernández, Adela, "Los niños expósitos de Úbeda (Jaén) y Sepúlveda (Segovia) en el Antiguo Régimen: las obras pías de San José y San Cristóbal”, en Campos y Fernández Sevilla, Francisco Javier (coord.), La Iglesia española y las instituciones de caridad. Actas del Simposium, San Lorenzo de El Escorial, Ediciones Escurialenses, 2006, p. 215.

${ }^{53}$ Cabe también la posibilidad de que la madre ahí fuera sorprendida por un parto repentino.
} 
hasta bien entrado el siglo xx. Las recién casadas, bien que ya hubieran creado su propio hogar, volvían a la casa materna para dar a luz su primer hijo ${ }^{54}$.

El lugar del nacimiento está dotado de significación cultural, se ve como factor condicionante de la salud y como augurio acerca del futuro del niño. Un tratado del tiempo — dirigido a damas de la élite de la sociedad - incluye largos pasajes sobre la influencia de la altura, la humedad, la temperatura durante la gestación y el parto. El autor, que es médico, insiste mucho en el derecho de una mujer gestante a elegir el lugar del nacimiento ${ }^{55}$. Una mujer de pueblo no tenía las mismas opciones que una aristócrata. Pese a ello, parece un dato muy a tener en cuenta que fuera la casa de la propia madre una de las opciones: la parturienta buscaba el apoyo de su propia progenitora, convertida en consejera y compañera en el parto. A falta de ella, la hermana mayor pudo suplir la carencia. Relaciones estrechas entre madre e hija, hermana mayor y hermana menor: se atisba ahí la dimensión histórica de un aspecto importante de la procreación ${ }^{56}$. Una madre podía guiar y acompañar a su hija en los asuntos más esenciales de la existencia humana. Esta observación está en consonancia con lo que sabemos sobre la formación de las comadronas. Solían aprender el oficio al lado de su propia madre y acceder al gremio por via hereditaria. Inés de Ayala, célebre en la Corte de España, constituye un ejemplo para ello.

\subsection{El agua: santificar el cuarto de parir}

Aunque se hablara de la "intención” de bautizar, lo que más se destacó en los testimonios de Barajas es el gesto de "echar agua" sobre el cuerpo que nace; lo que más importó fue la manipulación del elemento ${ }^{57}$, elemento visible y tangible, que se puso en contacto con la piel de una criatura que acababa de salir de su envoltura líquida.

¿“Tenía agua” el niño? ¿Qué tipo de agua se había usado? ¿En qué parte se había echado? Estas cuestiones importaron mucho y conformaron la mayor parte de los interrogatorios. Dan fe de una mentalidad que no concebía como efectiva una acción ritual sin sus señales exteriores,

\footnotetext{
${ }^{54}$ Domínguez Moreno, José María, "El ciclo vital en la provincia de Cáceres: Del parto al primer vagido", en Revista de Folklore, vol. 6a, 61 (1986), p. 8 [se reproduce la paginación de la versión digital]. «http://www. cervantesvirtual.com/nd/ark:/59851/bmcc26q1» [consultado el 15 de junio 2019].

${ }^{55}$ Ver Kremmel, Nina, "Pregnancy: Privileges and Protection in the Spanish Golden Age", en Hipogrifo, vol. 6, 1 (2018), pp. 467-481. DOI: https://doi.org/10.13035/H.2018.06.01.33

${ }^{56}$ Armengol Asenjo, Rebeca et al. "Psycho-Social Aspect in the Gestation: the Questionaire of Prenatal Evaluation", en Anales De Psicología / Annals of Psychology, vol. 23, 1 (2007), pp. 25-32. «https://revistas.um.es/analesps/ article/view/23241» [consultado el 10 de junio 2019].

${ }^{57}$ Los teólogos del tiempo exigen como "verdadera materia del bautismo cualquiera agua verdadera de cualquiera género que sea, ora del mar, ríos, lagunas, pozos, fuentes, baños”. Prohiben el uso de licores, de sudor, leche, orina, lágrimas o saliva. En caso de urgente necesidad, sin embargo, se puede echar mano de agua rosada, zumo de hierbas, caldo de carne, lejía, hielo, rocío, nieve por derretir, incluso de "agua turbia y hedionda", con tal que se administre sub conditione y con la fórmula modificada si aqua, qua utor, est materia Baptismi sufficiens, ego te baptizo: si non est, non te baptizo. De no darse la necesidad, el empleo de líquidos inmundos es pecado mortal de sacrilegio. Mota, Francisco de la, Compendio..., op. cit., pp. 592-593. Ver también Del Río Parra, Elena, "Bautismos con nieve, ayuno de olores y exhumación de cadáveres: casuística áurea y materialidad ritual", en eHumanista, 7 (2006), s.p.
} 
una mentalidad para la cual lo abstracto y lo espiritual no podía darse sin su contraparte concreta. Este énfasis podría sorprender a una sensibilidad moderna, habituada a anteponer el concepto y la creencia al manejo de sustancias y objetos rituales ${ }^{58}$. De este modo, se establecen correspondencias con el proceso fisiológico del embarazo y del parto, en los cuales el agua es elemento y metáfora principal; píensese en el líquido amniótico, o en expresiones del estilo como "romper aguas". Estos aspectos líquidos del nacimiento biológico se hallan a poquísima distancia temporal del agua como expresión simbólica de un segundo nacimiento espiritual y de la adhesión a las enseñanzas y ritos de la Iglesia católica ${ }^{59}$.

De acuerdo con los resultados arrojados por nuestro sondeo, hasta una quinta parte de los partos fueron seguidos de un bautismo de emergencia. Es más que probable, entonces, que esta posibilidad arrojara su sombra sobre todos los partos: era necesario tener agua preparada para esta eventualidad. La necesidad de tener que enlazar el proceso fisiológico con el acto religioso habría incrementado en los casos en que el embarazo ya transcurrió con complicaciones o el parto se inició antes de lo previsto ${ }^{60}$.

\subsection{Los actores principales y el peso de la responsabilidad}

La madre. El mundo católico tradicional, a la hora de bautizar, relega a la madre a un segundo plano ${ }^{61}$. Se anota su nombre en la partida y se confirma el vínculo materno con el recién bautizado, nada más. No se observa ningún acto, ninguna iniciativa o intervención activa de parte de la persona que más ha dado y más ha sufrido en el acto. Tal afirmación parece tener su validez para los partos legítimos que se administraron en el seno de la familia. Otro habrá sido el procedimiento cuando nació un niño que los padres - en no pocos casos son los padres y no las madres - destinaron a sobrevivir sin ser atendido por ellos. Estos niños expósitos, encontrados en las puertas de las casas cuna o de casas de particulares, con frecuencia llevaban una cédula ${ }^{62}$ que daba alguna información sobre su identidad y las causas de su abandono. En

\footnotetext{
${ }^{58}$ Ver sobre el debate en tiempos de Reforma y Contrarreforma Cressy, David, Birth, Marriage and Death, Oxford, Oxford University Press, 1997, pp. 108-123.

${ }^{59}$ En 1537, en la localidad toledana de Santa Olalla, una partera se lleva ante los jueces de la Inquisición por no haber cumplido "la aspersión del agua sobre [una] recién nacida durante el ritual del bautismo", Pelaz Flores, Diana, "El servicio de las parteras musulmanas en la Corte castellana bajomedieval a través de las Crónicas y otros testimonios documentales", en Amrán, Rica y Antonio Cortijo Ocaña (eds.), Minorías en la España medieval y moderna (ss. XV-XVII), Santa Barbara, University of California, 2016, p. 185.

${ }^{60}$ Es de notar que en la pintura religiosa no suele faltar el baño que se ha preparado para el niño que acaba de nacer.

${ }^{61}$ El bautismo se celebraba antes de que la madre saliera a "misa de purificación o misa de parida". Por lo tanto, no formaba parte de la comitiva que se encaminaba a la iglesia parroquial con la criatura en brazos del padre, de la abuela o de la comadre. La madre todavía guardaba cama ganando fuerzas con sopas y la carne de aves de corral. Usunáriz, Jesús M., "El «oficio de comadres» y el «arte de partear». Algunos apuntes sobre Navarra: siglo XVI-XVIII", en Arellano, Ignacio (ed.), Modelos de vida en Navarra de la temprana modernidad, Nueva York, Idea, 2016, p. 326. Ella falta en el momento en que el niño es introducido en la comunidad de los creyentes. Pero este proceder está en consonancia con la esencia del bautismo: ¿no quiere este añadir al parentesco de sangre, tachado del pecado original, otro más puro y espiritual?, Sánchez Diego, Héctor, Padrinazgo bautismal... op. cit., pp. 4552.

${ }_{62}$ AHDM, Fondo parroquial de San Justo y Pastor, Libro 6 de Bautismos, N ${ }^{\circ}$ Prov. 988, 10.4.1616-31.12.1621, fol. $84 \mathrm{v}$.
} 
no pocos casos se suele hacer mención de un bautismo de urgencia, suministrado al niño antes de entregarlo a la merced de otros. Suponiendo que muchos de estos niños nacieron sin que nadie asistiera a la madre, también podemos conjeturar que en estos casos fuera la madre quien llevó al cabo la ceremonia con valor sacramental ${ }^{63}$.

Los varones. En lo que se refiere al Siglo de Oro español, debería abandonarse la idea del parto como momento y lugar del que quedaron rigurosamente excluidos los hombres. Los hombres no se admitían en la zona más íntima del acontecimiento, es cierto, por lo menos en cuanto el parto se presentó sin complicaciones, pero más de un testimonio indica su presencia en el cuarto de parir, o por lo menos su cercanía y voluntad a asistir en servicios secundarios ${ }^{64}$. El bautismo de socorro fue un factor que obró en favor del elemento masculino ${ }^{65}$. Como hemos visto, en las parroquias madrileñas solían ser hombres con educación universitaria o que desempeñaron algún cargo eclesiástico los que llevaron a cabo la ceremonia. Parecen faltar estos varones con formación teológica en San Pedro de Barajas. Sin embargo, el testimonio de febrero de 1663 menciona como bautizante a un hombre, el tío del niño.

La abuela. De entre todos los familiares, es la abuela quien más hace sentir su asistencia, vigilancia y autoridad. Se ha visto que fue frecuente que ella abriera su casa para que allí se diera a luz. Y aun cuando no figurara de anfitriona de parto, estuvo presente y activa en el cuarto de parir. Luego en la iglesia refirió la versión del curso de los acontecimientos que se tomó por verídica. En dos de los casos presentados asume el papel de madrina de bautismo ${ }^{66}$. La abuela, pues, de estar viva, está presente en todo el proceso. No obstante, parece significativo que, en el caso del año 1663, cediera el paso a su yerno cuando se trató de bautizar con urgencia, de verter el agua según el mandato de la Iglesia y de recitar la fórmula pertinente.

\footnotetext{
${ }^{63}$ Ver - con testimonios del siglo xviII - Linage Conde, Antonio, "Algunos primeros y últimos viajes y ayudas para el camino en la Sepúlveda del Antiguo Régimen”, en Homenaje al profesor José Antonio Escudero, 4 (2012), pp. 583-586. Un ejemplo de la parroquia de San Justo y Pastor se encuentra en AHDM, Fondo parroquial de San Justo y Pastor, Libro 6 de Bautismos, N ${ }^{o}$ Prov. 988, 10.4.1616-31.12.1621, fol. 84v. Según el mandato de la Iglesia los padres solo pueden bautizar en caso de extrema necesidad: "Pater, aut mater propriam prolem baptizare non debent, praeterquam in mortis articulo, quando alius non reperitur, qui baptizet: neque tunc ullam contrahunt cognationem, quae matrimonii usum impediat", Rituale Romanum ... op. cit., p. 8.

${ }^{64}$ Ver para los años de Felipe II, Sánchez, Magdalena, "«I would not feel the pain if I were with you»: Catalina Micaela and the Cycle of Pregnancy at the Court of Turin, 1585-1597", en Social History of Medicine, vol. 28, 3 (2015), pp. 455, 457. Dulmovits, Alice-Viktoria, "Unseen Heirs. Written Traces of Pregnant Widows and Posthumous Children in Early Modern Spain (1490-1673)", en Hipogrifo, vol. 6, 1 (2018), pp. 442. DOI: https:// doi.org/10.13035/H.2018.06.01.31

${ }^{65}$ Algunos testimonios cortesanos, salvando las distancias, podrían tener valor indicativo. Así, el poderoso capellán y limosnero mayor del rey Felipe III, Diego de Guzmán, escribe en su biografía de la reina Margarita de Austria acerca del nacimiento del infante Fernando, que aconteció el 16 de mayo de 1609: "[...] a medio día me envió su majestad a mandar fuese al aposento de la reina, que estaba con dolores de parto, y que tuviese alli recaudo [sic] para baptizar lo que naciese (prevención Christiana y discreta) y a las dos, estando diciendo el segundo psalmo de los maitines de Navidad el convento de los religiosos de S. Lorenzo el Real, parió su magestad un infante muy lindo". Ver Guzmán, Diego de, Vida y muerte de Doña Margarita de Austria. Reina de España, Madrid, Luis Sánchez, 1617, fols. 188r-188v. La misma fuente refiere el bautismo de emergencia oficiado en el infante Carlos, nacido antes del tiempo y con peligro de vida en 1607 . Ver Guzmán, Vida ... op. cit., fol. 188v.

${ }^{66}$ Además, la abuela solía tenerse muy en cuenta al elegir el nombre de la nieta. Ver por ejemplo Carretero Melo, Onomástica... op. cit., p. 236. Es un hecho que igualmente subrayan estudios sobre otras regiones de Europa. Ver por ejemplo Morel, Marie-France, "La mort d'un bébé au fil de l'histoire”, en Spirale, vol. 31, 3 (2004), p. 16. DOI: https://doi.org/10.3917/spi.031.0015
} 


\subsubsection{La comadre: estrategias para evitar graves culpas}

El bautismo de socorro, tal como se parece haber administrado en San Justo y Pastor de Madrid y en San Pedro de Barajas a mediados del siglo XVII, dotó a la comadrona de autoridad, no cabe duda de ello. Pero también cargó sobre ella graves responsabilidades. Las acciones que emprendió durante el parto se controlaron, se sometieron a examen y se le exigió que pudiera dar cuenta de sus actos. Al mismo tiempo, con frecuencia es a ella a quien se confirió el derecho de difundir la verdad oficial sobre los acontecimientos peri- y postnatales. En los ejemplos aducidos aquí, dos veces fue la misma partera quien respondió al cura párroco. En los otros casos, fue la abuela, es decir, una mujer que habría colaborado estrechamente con la matrona. Primó también en esto el elemento femenino.

La posición privilegiada concedida a la comadrona en el bautismo de emergencia quedó confirmada por su presencia en el bautismo solemne, donde no fue raro que ella figurara como madrina de bautismo. Encontramos casos tanto en San Justo y Pastor como en Barajas ${ }^{67}$.

La comadre dirigió el Sacramento, pronunció las palabras rituales y vertió el agua que iba a efectuar el cambio en el estado del niño que tanto importaba a los católicos de la época. Es más, al iniciar el ritual religioso, al proceder al bautismo de urgencia, la comadre emitía un juicio sobre el estado del feto o niño recién nacido, estableciendo la línea entre la vida y la muerte y señalando con ello dos caminos opuestos: si el bebé se daba por muerto, no era lícito bautizar, incluso se consideraba un acto sacrílego ${ }^{68}$; si se detectaban indicios de vida, precisaba bautizar con la máxima presteza.

El asunto, pues, se presentó como delicadísimo: bautizar donde no había vida era pecado, pero en caso de no aprovechar los últimos momentos de vida para bautizar, la comadre se veía expuesta a graves acusaciones puesto que el niño que moría sin agua sacramental, según la visión oficial de la Iglesia, no podía acceder al paraíso. En un escenario en que la comadrona procuraba la entrada al mundo y sin solución de continuidad "anunciaba" el inminente paso a la muerte, ¿no sería ella la primera en tener que dar cuenta de su juicio erróneo, su falta de atención, su criminal negligencia o incluso su secreta complicidad con el diablo, a quien quiso brindar un alma inocente? ${ }^{69}$. Usunáriz, en su estudio sobre el oficio de la comadre, aporta dos causas criminales, en la primera una comadre es acusada por no bautizar a un niño aunque ya

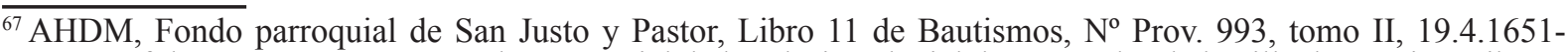
2.5.1659, fols. 2r y 3r. AHDM, Fondo parroquial de la Iglesia colegial de San Pedro de la villa de Barajas, Libro 5 de Bautismos, 1660-1663, fol. 37r. A la luz de testimonios sobre personajes eminentes del siglo se podría esperar una cota más alta. Así, por ejemplo, en enero de 1613, recibió el Sacramento el hijo de Luis Vélez de Guevara en la parroquia de San Andrés; asume la función de madrina "la comadre que trujo el niño a la pila", Cotarelo y Mori, Emilio, Luis Vélez de Guevara y sus obras dramáticas, Madrid, Tipografía de la Revista de Archivos, Bibliotecas y Museos, 1917, p. 30.

${ }^{68}$ Gélis, Les enfants... op. cit., pp. 40-41.

${ }^{69}$ Ezquerro, Andrea A., Mujeres, Brujas y Parteras en la Edad Moderna: Historia de una Persecución. pp. 2324. «http://www.academia.edu/9796814/Mujeres Brujas y Parteras en la Edad Moderna Historia de una Persecución»" [consultado el 21 de septiembre de 2018]; Tausiet Carlés, María, "Comadronas-brujas en Āragón en la Edad Moderna: mito y realidad", en Manuscrits, 15 (1997), pp. 379-380.
} 
sacara "el brazo tres veces". El documento es de 1530. En el segundo, del año 1629, el fiscal acusa a varias mujeres del "grave delito" de no haber bautizado a una niña antes de que muriera, a pesar de haber tenido ocasión para ello ${ }^{70}$. Además, si la comadre no daba el bautismo de manera correcta, el niño no se consideraba armado y protegido contra las fuerzas del diablo dispuestas a acosarlo ya mientras viviera ${ }^{71}$.

En vista de los estudios sobre el tema, se puede suponer que estos temores fueron bien difundidos en el siglo XVII y que las comadres habían elaborado sus estrategias para evitar graves conflictos tanto con los familiares del niño como con las autoridades. Volviendo una vez más a las cuatro estampas de interrogatorios arriba presentadas, se pueden detectar tres actitudes: primero, ante la duda, las comadres optan por bautizar, aunque después resultara que no hubo necesidad absoluta. Las expresiones que se emplearon ante el párroco apuntan hacia esta actitud: por estar dudosa del parto por el peligro con que nació el dicho niño: no hay certeza de muerte, pero hay temores y peligro. No pocos niños así bautizados superaron las dificultades del parto y siguieron con vida, el gran número de bautismos completados o confirmados sub conditione lo demuestra y es en sí prueba de que las obstetras actuaron con gran cautela; prefirieron bautizar con celo exagerado a correr el riesgo de ser inculpadas por la perdición de un alma inocente.

El afán bautizante parece que fue una de las estrategias adoptadas por las comadres, la segunda sería la generosidad e inventiva en lo que a la definición de la vida atañiera. Cuando estaban en juego la salvación del alma y el consuelo de los padres, justificarían el bautismo con cualquier indicio de animación en el cuerpecito del bebé, por muy discreto y efímero que fuera. Más adelante se aducirá una fuente de la época que respalda esta tesis: las comadronas aseguraron la salvación del alma negando o postergando la muerte del cuerpo.

De los testimonios dejados por los párrocos de San Pedro de Barajas se puede deducir una tercera posibilidad y estrategia de la cual se valieron las comadronas: bautizar en la fase perinatal. Vimos que en dos de los cuatro casos que debatimos se vertió agua ya antes de que el cuerpo del niño naciera por completo, un procedimiento que, por cierto, ya se exige en disposiciones eclesiásticas de comienzos del siglo XIV $^{72}$. A modo de hipótesis, que pide ser confirmada por estudios más amplios, se puede proponer que con frecuencia las comadronas se adelantaron al momento en que acaso difícilmente hubieran podido negar una evidencia irrefutable; procuraron la salvación evitando que se hiciera patente la muerte.

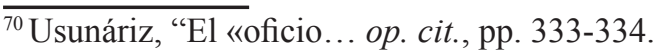

${ }^{71}$ El asunto se trata en la obra titulada Pleito que tuvo el diablo con el cura de Madrilejos, Rojas Zorrilla, Francisco de, Luis Vélez de Guevara y Antonio Mira de Amescua, "Pleito que tuvo el diablo con el cura de Madrilejos", en Doce comedias, las más grandiosas que hasta ahora han salido, Lisboa, Pablo Craesbeeck, 1653, pp. 295-338. Ver sobre esta obra, Madroñal, Abraham, "Lenguaje e historia: El Pleito que tuvo el diablo con el cura de Madrilejos", en Castilla Pérez, Roberto y Miguel González Dengra (eds.), La teatralización de la historia en el Siglo de Oro español. Actas del III Coloquio en Granada del 5 al 7 de noviembre de 1999 y cuatro estudios clásicos sobre el tema, Granada, Universidad de Granada, 2001, pp. 329-338.

${ }^{72}$ Ver Sarduy Nápoles, Miguel R. et al., "La cesárea como la más antigua de las operaciones obstétricas", en Revista Cubana de Obstetricia y Ginecología, vol. 44, 2 (2018), p. 5.
} 
El bautismo de urgencia les dio a las comadres españolas una autoridad religiosa ${ }^{73}$ que en regiones reformadas de Europa ya no se quiso conceder al género femenino ${ }^{74}$. Pero hay comadres y comadres, conviene diferenciar y matizar: los testimonios examinados procuran dar informaciones precisas acerca del estatus de la mujer que asiste en el nacimiento: comadre de la villa, comadre aprobada, o también una mujer que trajeron de fuera para que sirviese de comadre. Sería interesante saber más sobre la formación y las credenciales, si tales hubo, de la mujer que trajeron de fuera. Pero se puede suponer que no gozó ni de la misma reputación ni de la misma confianza que la comadre de la villa. Los detalles de la entrevista con el cura párroco bien podrían ser significativos a este respecto: la comadre forastera no testifica en la iglesia; la abuela del niño a quien compite referir los actos y palabras de la matrona no quiere atestar la ejecución correcta del bautismo y el párroco, bautiza sub conditione. La comadre de la villa, en cambio, parece mantener una relación de confianza con el representante de la Iglesia. En el bautismo solemne de diciembre de 1660, arriba referido, asegura que todo se había hecho según los preceptos eclesiásticos. El párroco se fía y se contenta con exorcizar y con procurar los óleos.

Estos testimonios divergentes podrían dar fe de un proceso de indoctrinación ya avanzado pero no acabado del todo. Los feligreses católicos no ignoraban la relevancia del asunto y tenían conocimientos elementales en cuanto a la ejecución de un bautismo. Sin embargo, y dado lo muy delicado del asunto, no todo el mundo se creía capaz de acertar con el gesto y la fórmula en el aprieto de un parto que se complica.

Cabe recordar también que la situación en San Justo y Pastor no corresponde al cien por cien a la de Barajas. Así, por ejemplo, la parroquia del centro de la corte de España demuestra un índice mucho más alto de bautizantes masculinos que la de San Pedro de Barajas. Entre ellos predomina el estamento eclesiástico. Tómese cualquier mes de las décadas centrales del siglo, se encontrarán menciones de presbíteros, frailes, jesuitas, licenciados y administradores de hospitales bautizando por necesidad ${ }^{75}$. Caben dos posibilidades: o bien los varones y eclesiásticos se llamaron durante el parto o justo después, cuando se daba la necesidad, porque gozaban de más confianza que la matrona. O también es posible que bautizaran a los niños que enfermaron en el intervalo entre el nacimiento y el bautismo solemne, puesto que no todos los bautismos de urgencia se administraban justo después del nacimiento del niño ${ }^{76}$.

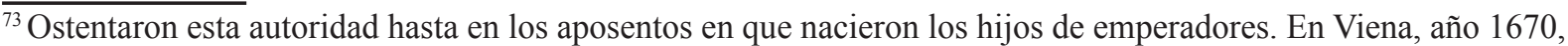
una comadre administró el bautismo de urgencia a Juan Battista, hijo de Margarita María de Austria. Ver Pötting, Franz Eusebius, Diario del conde de Pötting, embajador del Sacro Imperio en Madrid (1664-1674), editado por Miguel Nieto Nuño, Madrid, Biblioteca Diplomática Española Sección Fuentes 1, 1993, vol. 2, p. 103.

${ }^{74}$ Calvino rechazó el bautismo de emergencia y quería acabar con toda mujer bautizante y toda comadre que pudiera echar el agua de socorro. Ver Franceschini, Chiara, Storia... op. cit., pp. 258-262. Con ello anticipa a las voces del siglo XVIII que no pueden aceptar que un niño sufra la eterna condena por la falta de cuidado de una mujer, ya sea una comadre, una nodriza o una criada, Franceschini, Chiara, Storia ... op. cit., p. 309.

${ }^{75}$ Ver, por ejemplo, AHDM, Fondo parroquial de San Justo y Pastor, Libro 10 de Bautismos, No Prov. 992, 1.1.164317.4.1651, fols. 150r, 152r, 169r, 183r.

${ }^{76}$ En Polonia, por ejemplo, en el año 1594, la comadre administra el bautismo de emergencia a la segunda hija de la reina Ana de Austria a los 26 días de su nacimiento. Leitsch, Walter, Das Leben am Hof König Sigismunds III. von Polen, Viena, Österreichische Akademie der Wissenschaften, 2009, vol. 3, pp. 1625-1626.
} 


\section{Una digresión: un bautismo de urgencia en la corte de Polonia}

Los resultados de nuestros análisis cobran más solidez si se cotejan con otros casos bien documentados del periodo. Provienen del mundo aristocrático, vinculado a España por relaciones de parentesco y por alianzas matrimoniales. Con independencia de las diferencias jerárquicas entre una corte y una parroquia conformada por una mayoría de gente común, proporcionan pistas para una comprensión de los valores y conceptos básicos de la época. Un ejemplo para ello lo ofrecen las muertes de Ana de Austria, reina de Polonia, y su hijo Christoph en $1598^{77}$. La reina polaca murió, embarazada y muy enferma, unos 40 días antes de la fecha calculada para el nacimiento. Los médicos formaron el juicio de que el niño que llevaba dentro había muerto también; sin embargo, un barbero cirujano abrió el cuerpo de Ana a la media hora de su defunción y extrajo un cuerpo bien formado y con todos los miembros; el infante no dio señales de estar vivo, y el confesor pasó un buen cuarto de hora esperando y sujetando el agua sin poder proceder al bautismo, a pesar de que las comadronas declararan con firmeza que percibieron vida en la criatura. Acto seguido, ellas envolvieron el cuerpo del infante en paños calientes, lo lavaron y lo arrimaron al fuego que ardía en una chimenea, tras lo cual el confesor también creyó ver claras señas de animación. El infante fue bautizado y murió al cabo de cinco "padrenuestros", según algunos, después de una hora de vida, según otros. Fue enterrado en la catedral de Cracovia, junto a su madre. Pero el asunto siguió repercutiendo en las cortes europeas en que residieron los parientes cercanos de la reina y de su hijo. Ante todo fue María de Austria-Estiria, la madre de Ana y abuela de la criatura, quien exigió informes precisos sobre lo sucedido, en especial sobre las señales de vida que justificaran el bautismo por necesidad ${ }^{78}$. Ante el estudioso de hoy en día se despliega un escenario, en el que todos los implicados estaban ansiosos por ver, incluso por producir, pruebas de vida donde era difícil encontrarlas. No obstante, la negación de la evidencia de la muerte no se efectuó sin un esfuerzo compartido para dar una apariencia de credibilidad a la mentira piadosa.

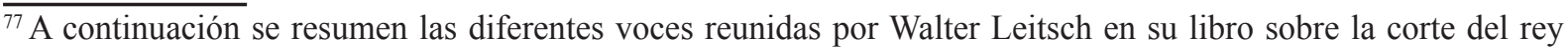
Sigismundo III de Polonia. Ibídem pp. 1721-1723.

${ }^{78}$ La camarera mayor no quiere comprometerse y se dice incapaz de afirmar nada al respecto. Otro cortesano facilita los indicios de los cuales depende la validez del Sacramento: refiere que el infante, bien en que en ningún momento abriera los ojos, sacudió los hombros y abrió la boquita. No abarcamos en esta ocasión el tema de los miracles à répit, mal estudiado para la Península Ibérica y actualmente sometido a revisión a base de un gran corpus de textos hagiográficos por Jesús M. Usunáriz, El parto como milagro, Ms., 2020.
} 
Perspectivas de investigación

El estudio del bautismo puede propiciar valiosos datos para una historia social y cultural del nacimiento, prueba de ello la dan los estudios pioneros de Jacques Gélis o los más recientes de Katherine Park ${ }^{79}$, Chiara Franceschini o Alessandra Foscati. Los proyectos que en el futuro desarrollen lo que aquí quedó esbozado podrían abarcar la gestación y la procreación en todas sus fases, desde la concepción hasta los cuidados al recién nacido. El ansia por no dejar morir a ningún feto sin el Sacramento podría haber incidido en los derechos y privilegios reservados a mujeres embarazadas y podría haber motivado esfuerzos por aumentar su protección ${ }^{80}$. El desarrollo, la admisión y la aplicación de nuevas técnicas operativas estuvo en relación directa con el bautismo; una de ellas fue la sección cesárea ${ }^{81}$, la extracción del feto de la madre, que en casi todas las fuentes se indica como muerta antes de que se practicara la intervención ${ }^{82}$. El cuerpo de la reina de Polonia, Ana de Austria, según indican las voces arriba presentadas, se abrió no para que el niño viviera sino para que no muriera sin haberse hecho cristiano. A pesar de ser patria de un santo que no llegó al mundo por parto vaginal — San Ramón Nonato ${ }^{83}$ todavía no se ha publicado ningún estudio extenso sobre la historia de la sección cesárea con enfoque en España. Quien lo emprenda deberá tener en cuenta las dimensiones religiosas del tema.

Por otra parte, la misericordia dispensada a los recién nacidos, a los huérfanos y niños expósitos, estuvo motivada por la política sacramental. El deseo de bautizar estimuló las obras caritativas pero también les impuso unos límites estrechos, dado que no se trató de abrir el camino hacia la vida sino hacia el cielo, donde el "ángel" que acabara de subir se tornara poderoso intercesor para los vivos. El Sacramento veló y dulcificó las muertes de bebés causadas por negligencia, enfermedad o falta de alimento. Las cotas de mortalidad en las casas cuna ofrecen un testimonio inquietante al respecto ${ }^{84}$.

La historia de la medicina, de la obstetricia y de las complejas formas de la religiosidad no se pueden escribir por separado. Una mujer que da a luz no es "un cuerpo" que expulsa a

\footnotetext{
${ }^{79}$ Park, Katherine, Secrets of Women. Gender, Generation, and the Origins of Human Dissection, Nueva York, Zone Books, 2010.

${ }^{80}$ Gélis, Jacques, Les enfants... op. cit., pp. 179, 193; Azpilcueta, Martín de, Compendio del manual de confesores y penitentes, Valladolid, Antonio Suchet en casa de Diego Fernández de Córdoba, 1586, fol. 248v. Ver Usunáriz, Jesús M., "El padre ante el parto en la España de los siglos XVI y XVII", en Hipogrifo, vol. 6, 1 (2018), pp. 483-502. DOI: https://doi.org/10.13035/H.2018.06.01.34

${ }^{81}$ Ver Foscati, Alessandra, "«Nonnatus dictus quod caeso defunctae matris utero prodiit». Postmortem Caesarean Section in the Late Middle Ages and Early Modern Period", en Social History of Medicine, vol. 32, 3 (2019), pp. 465-480. DOI: https://doi.org/10.1093/shm/hky022. Foscati, Alessandra, "Venire alla luce e rinascere. Il cesareo da madre morta e il miracolo à répit nel tardo Medioevo", en Foscati, Alessandra et al. (eds.), Nascere. Il parto dalla tarda antiquità all'età moderna, Bolonia, Il Mulino, 2017, pp. 95-114. Filippini, Nadia Maria, La nascita straordinaria. Tra madre e figlio la rivoluzione del taglio cesareo (sec. XVIII-XIX), Milano, Franco Angelo, 1995.

${ }^{82}$ Ver los ejemplos presentados por Sarduy Nápoles, La cesárea ... op. cit., pp. 5-6.

${ }^{83}$ Ver Usunáriz, "El «oficio... op. cit., pp. 341-342.

${ }^{84}$ Ver Tarifa Fernández, Adela, Los niños expósito ... op. cit., pp. 198-199. Ver también Gélis, Jacques, Les enfants ... op. cit., p. 193.
} 
otro "cuerpo". El elemento cultural no es adorno ni superestructura cultural, es un factor que entra en interacción con todos los otros factores. Nuestros casilleros académicos no sirven, ni para el Siglo de Oro ni para ningún otro siglo. Si queremos comprender los actos humanos en toda su complejidad debemos tener en cuenta las interpretaciones del mundo y del cielo que los guiaron. 